\section{Proteasome subunits encoded by the major histocompatibility complex are not essential for antigen presentation}

\author{
Frank Momburg*, Vianney Ortiz-Navarrete*, \\ Jacques Neefjes*, Els Goulmy $\dagger$, \\ Yvonne van de Walt, Hergen Spits $\neq$, \\ Simon J. Powis $\$$, Geoffrey W. Butcher\$, \\ Jonathan C. Howard\$, Peter Walden\| \\ \& Günter J. Hämmerling*
}

\begin{abstract}
* Tumor Immunology Program, German Cancer Research Center. Im Neuenhermer Feld 280, 6900 Heidelberg, Germany

1 Department of Immunohaematology and Blood Bank, University Hospital, Bldg 1 E3-Q, PO Box 9600 ,

2300 RC Leiden, The Netherlands

‡DNAX Research Institute, 901 Calıfornı Avenue Palo Alto, Calıfornıa 94304, USA

§ Department of Immunology, Agricultural and Food Research Council, Instıtute of Anımal Physıology and Genetıcs Research, Babraham, Cambridge CB2 4AT, UK

|| Max-Planck Institute for Bıology, Corrensstrasse 42, 7400 Tubıngen, Germany
\end{abstract}

MAJOR histocompatibility complex (MHC) class I molecules bind and deliver peptides derived from endogenously synthesized proteins to the cell surface for survey by cytotoxic $T$ lymphocytes. It is believed that endogenous antigens are generally degraded in the cytosol, the resulting peptides being translocated into the endoplasmic reticulum where they bind to MHC class I molecules. Transporters containing an ATP-binding cassette encoded by the MHC

TABLE 1 Presentation of the minor 'Istocompatibility antigen HA-2 by T2 cells transfected $w$ th transporter genes

\begin{tabular}{lcccccc} 
& \multicolumn{3}{c}{ Effector cel's } & & & \\
& AntI-HLA-A2 1 allo & \multicolumn{2}{c}{ AntI-HA-2 } & \multicolumn{2}{c}{ Q669 } \\
Target cells & 101 & 11 & 101 & 11 & 101 & 11 \\
$X$ & 71 & 57 & 68 & 43 & 1 & 1 \\
$Y$ & 72 & 60 & 55 & 26 & 0 & 0 \\
T1 & 96 & 82 & 71 & 64 & 10 & 5 \\
T2 & 100 & 87 & 0 & 1 & 2 & 1 \\
T2/TAP1 & $10 \mathrm{C}$ & 83 & 0 & 3 & 0 & 1 \\
T2/TAP2 & 81 & 61 & 5 & 5 & 3 & 1 \\
T2/TAP1 +2 & 82 & 75 & 57 & 26 & 0 & 0 \\
\hline
\end{tabular}

T2 cells transfected with rat TAP1 ${ }^{a}$ and $T A P 2^{a}$ CDNAs were tested for their capacity to present the endogenously synthesized minor histocompatibility antigen HA-2 to an HLA-A2 1-restricted minor histocompatibility antıgen HA-2-specific CTL clone T2 cells transfected with both transporter genes but not the untransfected T2 could present the HA-2 antigen An alloreactive CTL clone specific for HLA-A2 1 and the influenza matrixespecific CTL clone Q66 9 (see Table 2a) were included as controls The HA-2-specific CTL clone, designated HA-2 (ref 25), and the HLA A21 alloreactive CTL clone $^{26}$ were mixed with chromium-labelled targets at effector-to-target ratios of 101 and 11 , and specific lysis was measured in a 4-h chromium release assay, values represent per cent specific lysis $X$ and $Y$ are lymphoblastold cell lines transformed by Epstein-Barr virus and obtained from HLA-A2 1-positive healthy individuals
TABLE 2 Presentation of Influenza matrıx proteın M1 by T2 cells transfected with transporter genes

(a)

Q66 9 Effector cells

\begin{tabular}{|c|c|c|c|c|c|c|c|c|}
\hline \multirow[b]{3}{*}{ Target cells } & \multirow{2}{*}{\multicolumn{4}{|c|}{$\begin{array}{l}\text { Influenza virus infected } \\
\text { (expt 1) }\end{array}$}} & \multicolumn{4}{|c|}{ M1 peptide 58-66 added } \\
\hline & & & & & & & $1 \mu$ & \\
\hline & 51 & 051 & 51 & 051 & 51 & 051 & 51 & 051 \\
\hline$x$ & 28 & 14 & $n t$ & $n t$ & 3 & 0 & 23 & 14 \\
\hline Y & 33 & 15 & $n t$ & $n t$ & 0 & 0 & 30 & 12 \\
\hline JY & $n t$ & $n t$ & 31 & 7 & 3 & 0 & 23 & 14 \\
\hline T1 & 50 & 18 & 62 & 17 & 0 & 0 & 68 & 19 \\
\hline $\mathrm{T} 2$ & 7 & 4 & 8 & 3 & 7 & 3 & 71 & 21 \\
\hline $\mathrm{T} 2 / \mathrm{TAP} 1$ & 8 & 3 & 12 & 5 & 6 & 4 & 62 & 31. \\
\hline T2/TAP2 & 4 & 1 & 5 & 2 & 6 & 0 & 70 & 25 \\
\hline $\mathrm{T} 2 / \mathrm{TAP} 1+2$ & 26 & 7 & 33 & $1 \overline{1}$ & 0 & 0 & 73 & 29 \\
\hline
\end{tabular}

(b)

4-30 Effector cells

\begin{tabular}{cccccc}
\hline $\begin{array}{c}\text { M1-vac infected } \\
\text { (expt 1) }\end{array}$ & \multicolumn{4}{c}{ M1 peptıde } & $58-66$ added \\
101 & 061 & 101 & 061 & 101 & 061 \\
72 & 32 & 8 & 1 & 80 & 24 \\
78 & 22 & 11 & 3 & 68 & 24 \\
4 & 1 & 8 & 0 & 80 & 21 \\
14 & 6 & 2 & 2 & 67 & 14 \\
7 & 2 & 1 & 0 & 77 & 21 \\
49 & 16 & 7 & 2 & 75 & 17
\end{tabular}

Control cells and $T 2$ cells transfected with rat TAP1 ${ }^{a}$ and TAP2 ${ }^{a}$ were Infected overnight with influenza virus Hongkong 68 and then tested for HLA-A2 1-mediated presentation of the influenza matrix antigen using the CTL clone Q669 The results from two representative experıments are shown (a) In additional experıments usıng recombınant vaccinıa virus producıng matrix proteın (M1-vac) and the M1-specific CTL line 4-30, similar results were obtained $(b)$ Table 2 also shows that all cell lines function as targets after preıncubation with exogenously added influenza matrix peptıde M58-66 (sequence ILGFVFTLTV) (a) Where Indicated, target cells were infected overnight with influenza virus Hongkong 68 Q66 9 is a CTL clone recognizing the influenza matrix-derived peptide M58-66 restricted by HLAA2 1 This clone was ralsed against the synthetıc peptide M58-66 (HS, unpubiıshed) Lysis was determined in a 4-h chromium-release assay at effector-to-target ratios of 51 and 051 For presentation of exogenously added peptide, target cells were preincubated with M58-66 peptide at $1 \mu \mathrm{g} \mathrm{ml} l^{-1}$ for $2 \mathrm{~h}$ before addition of the CTL clone Q669 (b) Target cells were infected with M1-vac 27 (20 PFU per cell) for $3 \mathrm{~h} 4-30$ is a fresh CTL IIne from an HLA-A2 1-positive donor raised against the synthetic peptide M55-73 ( $\mathrm{PW}$, unpublished) Lysis was determıned in a 5-h chromıum-release assay at effector-to-target ratios ranging from 101 to 031 M58-66 peptide was added as a control 15 min before addition of CTL at $\left.25 \mu \mathrm{g} \mathrm{m}\right|^{-1}$

class II region seem to be responsible for this transport ${ }^{1-8}$. Genes coding for two subunits of the ' $20 \mathrm{~S}$ ' proteasome (a multicatalytic proteinase) have been found in the vicinity of the two transporter genes in the MHC class II region, indicating that the proteasome could be the unknown proteolytic entity in the cytosol involved in the generation of MHC class I-binding peptides ${ }^{9-13}$. By introducing rat genes encoding the $\mathrm{MHC}$-linked transporters into a human cell line lacking both transporter and proteasome subunit genes, we show here that the MHC-encoded proteasome subunits are not essential for stable MHC class I surface expression, or for processing and presentation of antigenic peptides from influenza virus and an intracellular protein.

The 20S proteasome consists of about 20-30 subunits with $M_{1}$ s between 15,000 and 30,000 that are encoded by distinct sets of genes ${ }^{14}$. We used the human lymphoblastoid B cell-derived mutant T2 line to investigate whether or not the MHC-linked proteasome subunits are essential for MHC class I expression and antigen presentation. T2 has a large homozygous deletion of the MHC class II region ${ }^{15}$, which encompasses the genes for the two ATP-binding cassette $(A B C)$ transporter polypeptides, TAP1 and TAP2, and the two genes for the MHC-encoded proteasome subunits, Lmp2 and Lmp7. In the absence of transporters, most HLA class I molecules are devoid of the peptides 
FIG 1 Restoration of HLA class I expression on T2 cells transfected with transporter genes The cDNAs for the two rat transporter chans TAP1a and TAP2a were used individually or as a mixture to transfect T2 cells HLA cellsurface expression was measured by cytofluorometry in five independent cotransfections with TAP1 and TAP2 we always obtained a substantial fraction of cells expressing high levels of HLA class I, similar to the example shown here METHODS In each experıment, $10^{7} \mathrm{~T} 2$ cells were transfected by electroporation with $\sim 2 \mu \mathrm{g}$ each of rat CDNAS TAP1 ${ }^{a}$ (mtp $1^{a}$, clone 510-15) or TAP2 ${ }^{a}$ ( $m$ tp $2^{a}$, clone 441-11) in the $\mathrm{pH} \beta \mathrm{APr}-1$-neo expression vector ${ }^{1521}$ Both plasmids contain the $\beta$-actin promoter and the neomycin-resistance gene Selection was in $1 \mathrm{mg} \mathrm{ml}^{-1} \mathrm{G} 418$ (Gibco) After 4 to 6 weeks, cytofluorometry was done with the bulk cultures using a FACScan (Becton and Dickinson) Antibodies used were Tu101 against HLA-A2 (ref 28), Tu109 against HLA-Bw4 (ref 29), and 206 against HLA-DR, -DP and -DQ (ref 30), detected by fluorescein isothiocyanate (FITC)-conjugated goat anti-mouse IgG (Sigma) Staınıng with antibodies Tu48 (HLA-Bw4, ref 31) and BB7 2 (HLA-A2; ref 32) yielded comparable results, except that BB7 2 stained HLA-A2 antigens on untransfected T2 cells more strongly than antibody Tu101 The unseparated bulk culture of T2 cotransfected with both transporters yielded a broad peak containing both negative and positive cells Bottom row shows staining profiles of T2/TAP1 +2 enriched by cell sorting for high expression of HLA-B5 using antibody Tu109 and FACStar Plus cell sorter

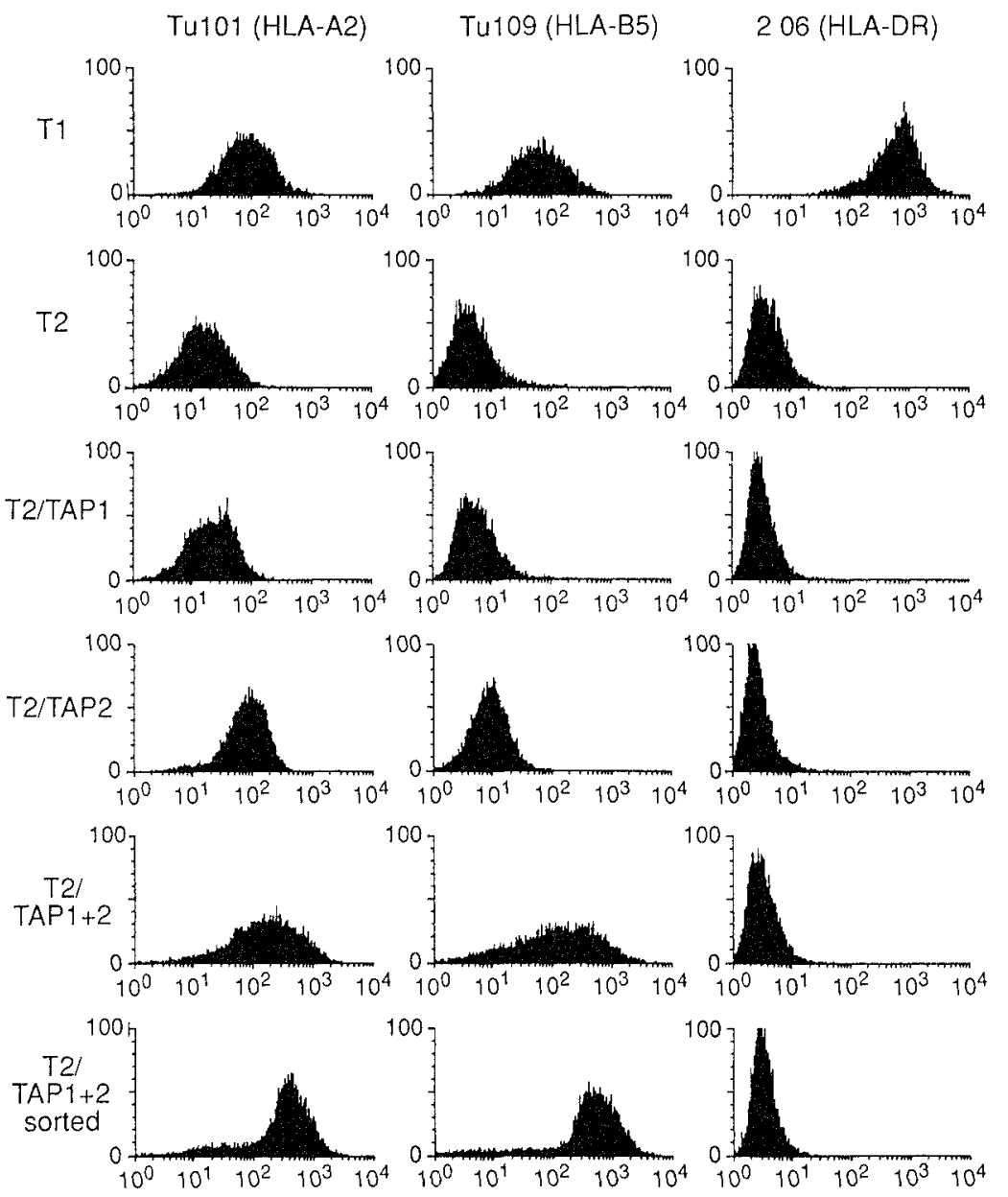

necessary for stable assembly of the class I heavy chain with $\beta_{2}$-microglobulin and for expression at the cell surface ${ }^{16-18}$ Therefore the $\mathrm{T} 2$ cell line shows strongly decreased expression of HLA-B5 and partially decreased expression of HLA-A2.1 molecules and is deficient in antigen presentation ${ }^{19,20}$.

We transfected the $\mathrm{T} 2$ cells with the rat $\mathrm{ABC}$ transporter complementary DNAs rat $T A P 1^{a}$ and rat $T A P 2^{a}$, previously named $m t p 1^{a}$ and $m t p 2^{a}$, respectively ${ }^{1,5,21}$. The resulting transfectants were analysed for class I cell-surface expression. Parental $\mathrm{T} 1$ cells, from which $\mathrm{T} 2$ cells were derived, were positive for HLA-A2.1 and -B5 and also for HLA class II molecules, whereas T2 cells did not stain for HLA-B5 and only weakly for HLA-A2.1 (Fig. 1). Transfection with rat TAP1 ${ }^{a}$ alone did not alter HLA expression. Transfection with TAP2 ${ }^{a}$ resulted in a slight increase of HLA-A2 and HLA-B5 expression, which we are investigating at present. But when both $T A P 1^{a}$ and $T A P 2^{a}$ rat transporter genes were transfected into T2 cells, HLA-A2.1 and HLA-B5 expression was restored to levels two to three times higher than on T1 cells. Expression of class $I$ in this bulk culture was improved by sorting for cells expressing high levels of HLA-B5 (bottom panel).

Western blots using sera raised against rat TAP1 and TAP2 showed that the T2/TAP1 +2 transfectant expressed the TAP polypeptides in amounts comparable to rat strain PVG.R19 lymphoblasts stimulated by concanavalin A (Fig. 2a). The absence of the MHC-encoded proteasome subunits in the T2 transfectants was confirmed by immunoprecipitation (not shown) and messenger RNA analysis (Fig. 2b). It is possible that in the absence of Lmp 2 and Lmp7, peptides of inappropriate length are generated, which would result in a decreased stability of the assembled class I molecules. Lysates of biosynthetically labelled cells were incubated at $37^{\circ} \mathrm{C}$ for different times. Class
I molecules were then immunoprecipitated with monoclonal antibody W6/32, which only recognizes class I molecules associated with $\beta_{2}$-microglobulin. Class I molecules devoid of peptides are unstable under these conditions and lose the epitope recognized by W6/32 (ref. 22). HLA-A2 and B5 were separated by one-dimensional ssoelectric focusing (Fig. 2c). Most HLA-A2 molecules expressed in $\mathrm{T} 2$ cells are unstable to exposure at $37^{\circ} \mathrm{C}$, whereas most HLA-A2 molecules in T1 cells and T2 cells reconstituted with TAP1 and TAP2 are stable over a 4-h exposure to $37^{\circ} \mathrm{C}$. A more drastic effect of temperature on the stability of HLA-B5 is evident. HLA-B5 in T2 cells is unstable at $37^{\circ} \mathrm{C}$, whereas it is stable both in T1 cells and in T2/TAP1 +2 cells. Thus, expression of TAP1 and TAP2 in T2 cells results in proper stabilization of both HLA-A2 and -B5 molecules. These results demonstrate that expression of transporter polypeptides alone, in the absence of the MHC-encoded proteasome subunits, is sufficient for apparently normal and stable class I expression.

Next, T2 cells transfected with rat $T A P 1^{a}$ and rat $T A P 2^{a}$ were investigated for their ability to process and present endogenous proteins. For this purpose $\mathrm{T} 2$ transfectants were tested with an HLA-A2.1-restricted cytotoxic T lymphocyte (CTL) clone recognizing a minor histocompatibility antigen (HA-2). Control cells, including T1, were lysed, but not T2 cells or T2 transfected with only one transporter gene (Table 1). In contrast, $\mathrm{T} 2$ cells transfected with both transporter genes were lysed efficiently. An HLA-A2.1 alloreactive CTL clone included as a positive control strongly lysed all transfectants, including the parental T2 cells. As the HLA-A2.1 molecules on T2 cells appear to carry only a limited variety of peptides derived from signal sequences ${ }^{23,24}$, our data suggest that the anti-HLA-A2.1 CTL clone recognizes such a signal sequence-derived peptide.

Because the nature of the HA-2 antigen is not yet known, we 


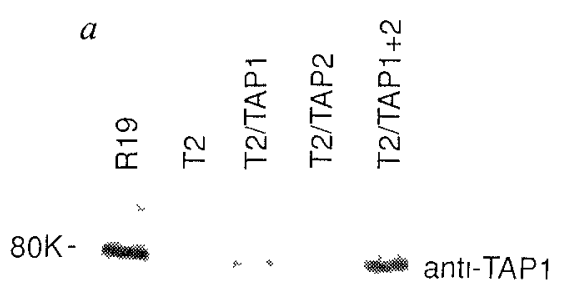

$80 K-$

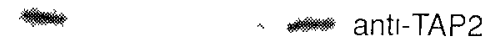

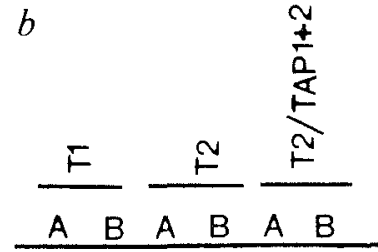

$-4.4 \mathrm{~kb}$

$-2.4 \mathrm{~kb}$

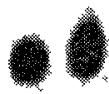

$14 \mathrm{~kb}$
FIG 2 Expression of TAP1 and TAP2 in T2 cells results in stabilization of HLA-A2 and HLA-B5 molecules a, Expression of ABC transporters in transfectant cells Rat PVG R19 lymphoblasts stımulated with concanavalın $A$ and lysed in NP40 detergent, and T2 and the single and double transfectant cells were probed with rabbit antisera raised against synthetic peptides of the carboxy termını of rat TAP1 ${ }^{a}$ and TAP2 ${ }^{a}$ The antisera fall to recognize material in T2 cells but detect rat TAP products in the transfectants Cell lysis and western blottıng were done as described ${ }^{5}$, each track contains lysate equivalent to 20,000 cells Antisera recognizing rat TAP1 (ref 5) and a new, previously undescribed antiserum raised against the rat TAP2 $\mathrm{C}$ termınal sequence EQDVYAHLVQQRLEA were used at a 1/1,000 dilution $b$, Northern blot analysis was used to verıfy that the T2 cells expressing rat TAP1 ${ }^{a}$ and TAP2 ${ }^{a}$ transporters were indeed negative for expression of the MHC encoded subunit Lmp7 Lanes show $20 \mu \mathrm{g}$ (lanes A) or $40 \mu \mathrm{g}$ (lanes B) total RNA extracted from each cell line and probed with a cDNA specific for Lmp7 (Isolated by Uwe Graf and VON, unpublished) The absence of the MHC-encoded proteasome subunits was also verified by immunoprecipltation (noc shown) using a rabbit serum against the $20 \mathrm{~S}$ proteasome ${ }^{11} C_{1}$ Stability of MHC molecules was assayed by exposing cell lysates to $37^{\circ} \mathrm{C}$ for different times Stable class I molecules were recovered with the monocional antibody W6/32 Both HLA-A2 and -B5 molecules are stabilized by expressing TAP1 and TAP2 in T2 cells and regain a sımilar stabilıty as class I molecules in T1 cells We labelled $14 \times 10^{6} \mathrm{~T} 1, \mathrm{~T} 2$ or T2/TAP1 +2 cells for $15 \mathrm{~m} / \mathrm{n}$ with $200 \mu \mathrm{Cl}^{35} \mathrm{~S}$-methınıne and cysteine, respectively

analysed the processing of a well-defined antigen, influenza virus matrix protein. Cells were infected overnight with influenza virus and then used as targets for the CTL clone Q06.9, which recognizes the influenza matrix-derived peptide epitope M58-66 restricted by HLA-A2.1. Representative experiments in Table $2 a$ show that infected T1 cells, the HLA-A2.1-pcsitive cell line $J Y$, and $X$ and $Y$ targets wese killed, but not $T 2$ cells or $T 2$ transfected with the individual transporter genes. In contrast, the T2/TAP1 +2 cells expressing both transforter polypeptides were lysed. This lysis (26 and $33 \%$ at a 5.1 effector to target ratio) was weaker than the lysis of $\mathrm{T} 1$ cells $(50 \%$ and $62 \%$, respectively) but with the other influenza virus-infected cell lines, JY, $\mathrm{X}$ and $\mathrm{Y}$, only 28 to $33 \%$ lysis was again obtained. Results were comparable when target cells were infected with a recombinant vaccinia virus making the influenza $\mathrm{M} 1$ matrix protein (M1-vac) and the M1-specific CTL line 4-30 was used (Table $2 b$ ). Lysis of M1-vac-1nfected T2/TAP1 +2 cells was again less than lysis of M1-vac-infected T1 cells. All transfectants were able to present the synthetic matrix peptide M58-66 when it was added exogenously. It is clear from these data that the capacity to form and present this influenza epitope has been returned to the T2/TAP1 +2 transfectant, although it is possible that this capacity is suboptimal.

We conclude that the heterodimeric MHC-encoded transporter is alone sufficient for MHC class I-mediated antigen presentation, at least for the two antigens tested here. Thus, there does not seem to be an absolute requirement for the MHC-linked proteasome subunits Lmp2 and Lmp7. Our observations could mean that the presence of genes encoding two of the proteasomes in the MHC may be fortuitous and that the $20 \mathrm{~S}$ proteasome does not play a role in antigen presentation. It is also possible however that the proteasome is only one of several proteolytic enzymes with the capacity to digest cytosolic antigen into class I-binding peptides. A proteasome lacking the MHC-encoded subunits may well have adequate proteolytic activity and could be the source of peptides assembled in our T2/TAP1 +2 transfectant. The MHC-encoded proteasome subunits, which are inducible by interferon- $\gamma$, may nevertheless function to increase the overall proteolytic activity or the range of peptides generated by the proteasome from antigens in the context of an immune response, to a virus for example. Investigation of $\mathrm{T} 2$ cells restored with transporters and of the MHC-encoded proteasome subunits will help to clarify this issue.

\footnotetext{
Received 5 June accepted 17 September 1992

1 Deverson $E V$ et al Nature 348, 738741 (1990)

2 Trowsdale $J$ et al Nature $348,741-744$ (1990)

3 Sples $T$ et al Nature 348, 744-747 (1990)

Monaco J J Cho S \& Attaya M Science 250,1723 1726 (1990)

Powis $S$ J et al Nature 354, 528-531 (1991)

Kelly A et al Nature 355, 641644 (1992)

Sples $T$ et al Nature 355, 644646 (1992)

8 Attaya $M$ et al Nature 355, 647-649 (1992)

9 Glynne $\mathrm{R}$ et al Nature $353,357360(1991)$
} 
10 Brown M G Driscoll J \& Monaco J J Nature 353, 355357 (1991)

11 Ortiz Navarrete $\vee$ et d Nature 353, 662-664 (1991)

12 Martinez C K \& Monaco \& f Nature 353, 664-667 (1991)

13 Kelly $A$ et al Nature 353,667 668 (1991)

14 Rivett A J Archs Blochem Blophys 268, 1-8 (1989)

15 Saiter $R$ D Howell D N \& Cresswell $P$ Immunogenetics 21, 235-235 (1985)

16 Townsend A et al Cell 62, 285295 (1990)

17 Kvist S \& Hamann U Nature 348, 446-448 (1990)

18 Ortiz Navarrete V \& Hammerling G J Proc natn Acad SCl US A 88, 3594-3597 (1991)

19 Cerundolo $V$ et al Nature 345, 449-452 (1990)

20 Hosken N A \& Bevan M J Scrence 248, 367370 (1990)

21 Powis $S j$ et al Nature 357, 211-215 (1992)

22 Baas E J et al J exp Med 176, 147-156 (1992)

23 Henderson R A et al Sclence 255, $12641266(1992)$

24 Wei M L \& Cresswell P Nature 356, 443446 (1992)

25 Goulmy E Transplant Rev 2, 2953 (1988)

26 Horat S v d Poel J \& Goulmy E Immunogenetics 16, 135-142 (1992)

27 Gotch F Rothbard I Howland K Townsend A \& MCMichael A Nature 326, 881-882 (1987)

28 Multer C Shı L Schneıder M Ziegler A \& Wernet P Hum Immun 6, 189-1.97 (1983)

29 Multer $C$ et al Hum immun 14, 333349 (1985)

30 Charron D I \& McDevitt H O Proc nath Acad Sci USA 76, 6567-6571 (1979)

31 Muller C Zlegler A Muller G Schunter F \& Wernet $P$ Hum Immun 5, 269-281 (1981)

32 Brodsky $F M$ Parham $P$ Barnstable $C$ ) Crumpton $M J$ \& Boomer $W F$ Immunol Rev 47, 3-61 (1979)

ACKNOWLEDGEMENTS We thank M Post for technical help A Arzberger for cell sorting A Ziegler for antibodies $V$ Cerundolo for $T 1$ and $T 2$ cells $A$ MclMichael for $M 1$ vac recombinant vaccinia virus $U$ Esslinger for preparation of the manuscript and C M Melıef for discussion This work was partially supported by the Deutsche Forschungsgemeinschaft SJP is supported by the UK Arthritis and Rheumatism Councll JN is supported by an EMBO fellowship 